\title{
Traditional eye medication and pterygium occurrence in Limpopo Province
}

P Anguria, S Ntuli, B Interewicz, T Carmichael

Background. The relative importance of environmental and hereditary factors in the occurrence of pterygium in African blacks has not been reported.

Aim. To investigate the relative significance of factors associated with pterygium occurrence.

Methods. This was a prospective case-controlled study where 150 pterygium patients and 150 controls participated. Interviews were conducted, eyes examined and multivariate analysis done. The families of 51 pterygium cases and 50 controls were examined for presence of pterygium.

Results. Of 150 cases and 150 controls, 79 (52.6\%) and 60 (40\%) used traditional eye drops (odds ratio (OR) 2.03; $p=0.009$. Ten cases $(6.6 \%)$ and 26 controls (17.3\%) had unstable tear film (OR $0.30 ; p=0.007$. Forty-six cases $(30.6 \%)$ and 15 controls (10\%) reported a positive family history (OR $3.93 ; p<0.001)$. Groups of $3-5$ pterygium cases in a household occurred in 36 of 51 pterygium families (70.5\%) v. 1 of 50 controls (2\%).

Conclusions. Pterygium occurrence was associated with the use of traditional eye drops, a positive family history and having groups of diagnosed pterygium-affected relatives. However, unstable tear film seemed protective against pterygium occurrence.

S Afr Med J 2012;102(8):687-690. DOI:10.7196/SAMJ.5930
Blacks in Africa use traditional medicine widely ${ }^{1}$ but there is no report of whether its topical use in the eyes is associated with pterygium occurrence. Excessive exposure to ultraviolet (UV) light based on location, ${ }^{2}$ occupation, ${ }^{3}$ and length of time spent outdoors ${ }^{4}$ is regarded as the main association of pterygium occurrence. However, a previous report has shown that pterygium cases were more frequent in the Karoo than the Transkei, areas that receive similar levels of UV light. ${ }^{5}$ Moreover, climatic droplet keratopathy and pingueculae, which are also associated with excessive sunlight exposure, did not occur together with pterygium significantly. ${ }^{5}$ Contrary to expectation, pterygium prevalence was found to be low in patients attending a referral hospital in Rwanda, which is close to the equator and at a high altitude. ${ }^{6}$ Those reports suggest that there was another factor besides UV light in pterygium occurrence.

Exposure to dust has been reported to be associated with pterygium $^{3,5}$ and heredity may also be a factor; ${ }^{8,9}$ however, single pedigrees were investigated, or the participants self-reported their family histories.

A relationship between dry eyes and pterygium has been claimed, ${ }^{10}$ yet has also been contradicted. ${ }^{9}$ Dry eye, whether associated with pterygium or not, has not been reported to be independent of other factors related to pterygium occurrence. Tobacco use has been reported to be associated, ${ }^{11}$ but also as being protective, ${ }^{12}$ and to have no relationship ${ }^{13}$ with pterygium presence. There is no report on a relationship between tobacco use and pterygium among blacks.

As the relative importance of hereditary and environmental factors in the occurrence of pterygium in blacks has not been reported,

Division of Ophthalmology, Department of Neurosciences, University of the Witwatersrand, Johannesburg

Peter Anguria, MB ChB, MMed Ophth

Trevor Carmichael, MB BCH, FCS (SA), PhD (Med), MSc (Med)

University of Limpopo, Polokwane Campus, Ga-Rankuwa

Sam Ntuli, BSc (Hon) Stat, MSc Biostat

Bozenna Interewicz, MD, $\mathrm{PhD}$ we aimed to determine the relative significance of the main factors associated with pterygium occurrence in rural blacks. Our objectives were to investigate whether environmental factors such as use of traditional eye drops, UV exposure, dust exposure, tobacco use, dry eye and family history were associated with pterygium, and whether pterygium clusters in rural black families.

\section{Methods}

This was a prospective case-controlled study, matched for age and sex, in Mankweng Hospital, Sovenga, which receives patients from all over Limpopo Province. The tropic of Capricorn crosses the province, which is predominantly rural, and is sunny and dry for most of the year. ${ }^{14}$

Ethical clearance was obtained from the two institutions' research ethics committees, and the tenets of the Declaration of Helsinki (2000) were followed in obtaining consent.

Eligible participants were consecutive black patients aged $21-65$ years who were born and living in a rural area. They were selected from the Outpatients Department in the Eye Unit. Those attending the eye clinic had primary pterygium; the controls, who were attending the refraction clinic, did not have pterygium and were not contact lens users. Cases and controls with previous ocular surgery or trauma, blepharitis or lid deformities, ocular surface malignancy, corneal scars, cataracts, maculopathy, glaucoma, optic atrophy or swelling were excluded. After obtaining consent, the selected individuals were recruited. A sample size of 300 (150 pterygium cases and 150 controls) was calculated to give a $20 \%$ difference in family history between cases and controls with a power of $80 \%$ and an alpha value of 0.05 , assuming a base rate of $10 \%$ in controls. Between August 2008 and 2011, 150 pterygium cases and 150 controls were interviewed using structured questions that had been used in an earlier study. ${ }^{9}$ A full eye examination was done. Demographic factors such as ethnic group and level of education were documented. The risk factors assessed were: use of traditional eye drops, occupational exposure to sunlight and dust, tobacco use, dry eye and family occurrence of pterygium.

Use of traditional eye drops was recorded. UV light was assessed by determining the daily mean hours of exposure to sunlight, which was calculated from time spent working outdoors and leisure time outdoors. The proportion of outdoor occupations as a percentage of all occupations was calculated. Exposure to dust while at work and whether tobacco had ever been used was verified. 
Familial occurrence was initially assessed by asking for family history. Such history was considered present if the pterygium patient or control said that a relative had or ever had a lesion on the eye that looked similar to a pterygium as shown to them in photographs.

The presence or not of dry eyes was evaluated by measuring the tear film break-up time (TBUT) as previously reported. ${ }^{9}$ The cornea was assessed for dark spots or streaks after application of fluorescein. The mean of three time intervals between blinks for the appearance of these areas was the TBUT, and a value $<10$ seconds was considered to indicate an unstable tear film (dry eye).

Follow-up family studies on selected cases and controls, who accepted a family visit and whose relatives were living within 20 $\mathrm{km}$ of each other within the rural areas of Limpopo Province were conducted. Families that did not possess diagnostic photographs of absent key members were excluded.

The key relatives of 51 pterygium probands and 50 controls were visited and the eyes of those $>9$ years old were examined by one ophthalmologist (PA) using a diagnostic lamp, for presence of pterygium. Nine years was chosen as a cut-off age because this is the youngest age reported at which pterygium has been diagnosed in black patients. ${ }^{5}$ Photographs of absent family members were examined by PA. Key relatives included siblings, parents, offspring, grandparents, first uncles and aunts, and the propositus.

Data on variables that were reported to be present in a patient and the control partner during the period before the person was diagnosed as having pterygium, and data from eye examination, as well as data from family studies, were considered. Descriptive statistics for pterygium cases and controls were summarised. Odds ratios (ORs) for the risk factors of pterygium were calculated by a conditional logistic regression model. In all models, a 1:1 pair-matched analysis was performed using age and gender as pairing variables. Statistical significance was tested by the chi-square test, and variables that were significant in the univariate analyses were included in a multivariate analysis. In all the analyses, significance was set at $p \leq 0.05$. STATA 9 for Windows software (STATA Corporation, College Station, USA) was used for statistical calculations.

To obtain a larger sample size for analysis in family studies, the key relatives of the case patients and those of the controls were combined into two separate large families. ${ }^{15}$ The difference in proportion of pterygium-affected individuals between the combined families of the cases and those of the controls was compared. The proportion of pedigrees having a group of pterygium-affected individuals was compared between cases and controls.

\section{Results}

One hundred and fifty pairs of cases and controls were interviewed and their eyes examined. Table 1 presents demographic factors and environmental factors not found to be significant. The most frequent age range was $40-49$ years. There were over $3 \frac{1}{2}$ times as many females as males. Education and ethnicity were similar among the cases and the controls.

Table 2 presents the count (percentage) and odds ratio (OR) of variables significantly associated with pterygium occurrence from the univariate analyses. The use of traditional eye drops and family history of pterygium were reported more frequently in pterygium patients. Dry eye was more frequent in controls.

Table 3 summarises a joint model of pterygium susceptibility with all variables listed in Table 2. All remained independently significant of one another. The pedigrees of 51 pterygium cases and 50 controls were visited. The families were located in the different regions of Limpopo Province; 382 individuals were examined in the combined families of pterygium cases and 394 in controls. Fourteen (3.6\%) of
Table 1. Demographic factors and environmental factors not significant

\begin{tabular}{lll}
\hline Factor & Cases (\%) & Controls (\%) \\
\hline Age & & \\
$20-29$ & $12(8)$ & $12(8)$ \\
$30-39$ & $23(15.3)$ & $54(15.3)$ \\
$40-49$ & $54(36)$ & $51(34)$ \\
$50-59$ & $51(34)$ & $10(6.6)$ \\
$\quad 60+$ & $10(6.6)$ & $118(78.6)$ \\
Sex & & $32(21.3)$ \\
Female & $118(78.6)$ & $114(76)$ \\
$\quad$ Male & $32(21.3)$ & $36(24)$ \\
Education & & $112(74.6)$ \\
$\quad \leq 12$ years & $106(70.6)$ & $38(25.3)$ \\
$>12$ years & $44(29.3)$ & $80(53.3)$ \\
Ethnic group & & $111(74)$ \\
Pedi & $111(74)$ & $126(84)$ \\
$\quad$ Other & $39(26)$ & $26(17.3)$ \\
Outdoor occupation & $80(53.3)$ & \\
Sunlight $\geq 6$ hr/day & $118(78.7)$ & \\
Dust exposure & $124(82.7)$ & \\
Tobacco use & $31(20.7)$ & \\
& &
\end{tabular}

Table 2. Risk factors found significant in univariate analysis

\begin{tabular}{lllll}
\hline Factor & Cases (\%) & Controls (\%) & OR & $p$ \\
\hline Traditional eye drops & $79(52.6)$ & $60(40)$ & 1.70 & 0.03 \\
Family history & $40(30.6)$ & $15(10)$ & 3.81 & $<0.001$ \\
Dry eyes & $10(6.6)$ & $26(17.3)$ & 0.33 & 0.007
\end{tabular}

Table 3. Multivariate analysis of significant factors

\begin{tabular}{lllll}
\hline Factor & Cases (\%) & Controls (\%) & OR & $p$ \\
\hline Traditional eye drops & $79(52.6)$ & $60(40)$ & 2.03 & 0.009 \\
Family history & $40(30.6)$ & $15(10)$ & 3.93 & $<0.001$ \\
Dry eyes & $10(6.6)$ & $26(17.3)$ & 0.30 & 0.007
\end{tabular}

382 family members of pterygium probands, and 17 (4.3\%) controls, were diagnosed by means of photographs. The age range of the family members was from 10 to 86 years, and the proportion of individuals aged $\leq 40$ years was $71.9 \%$ (275 of 382 ) in pterygium cases and $72 \%$ (284 of 394) in controls. The pterygium probands had 56 combined offspring aged $\leq 20$ years, of whom 3 (5.4\%) were affected. Two - 14 individuals in a family were examined among the case pedigrees, and $4-12$ in control pedigrees. Thirty-four (66.7\%) of 51 case families and $33(66 \%)$ of 50 control families had 6 - 9 individuals in a household, which was the median and also the most frequent range of family size. We found that 157 (41\%) of 382 combined key relatives in cases were pterygium-affected, and 16 (4\%) of 394 in the combined control pedigrees were pterygium-affected.

Table 4 presents the number of pedigrees of cases and controls in relation to the number of family members and number of individuals affected in a household. Larger families tended to have more 
Table 4. Distribution of pterygium-affected individuals in families

\begin{tabular}{|c|c|c|c|c|c|c|c|c|c|c|c|}
\hline & \multicolumn{11}{|c|}{ Case pedigrees: number of individuals in family } \\
\hline & & $\leq 4$ & 5 & 6 & 7 & 8 & 9 & 10 & 11 & 12 & 14 \\
\hline \multirow{8}{*}{$\begin{array}{l}\text { No. of individuals affected in a } \\
\text { family }\end{array}$} & 0 & 0 & 0 & 0 & 0 & 0 & 0 & 0 & 0 & 0 & 0 \\
\hline & 1 & 2 & 3 & 2 & 1 & 0 & 0 & 0 & 0 & 0 & 0 \\
\hline & 2 & 1 & 3 & 0 & 1 & 1 & 1 & 0 & 0 & 0 & 0 \\
\hline & 3 & 0 & 0 & 5 & 2 & 1 & 3 & 1 & 0 & 1 & 0 \\
\hline & 4 & 0 & 0 & 7 & 0 & 1 & 7 & 1 & 2 & 0 & 1 \\
\hline & 5 & 0 & 0 & 0 & 1 & 1 & 0 & 0 & 1 & 0 & 1 \\
\hline & \multicolumn{11}{|c|}{ Control pedigrees: number of individuals in family } \\
\hline & & $\leq 4$ & 5 & 6 & 7 & 8 & 9 & 10 & 11 & 12 & 14 \\
\hline \multirow{6}{*}{$\begin{array}{l}\text { No. of individuals affected in a } \\
\text { family }\end{array}$} & 0 & 3 & 3 & 5 & 2 & 7 & 10 & 4 & 1 & 2 & 0 \\
\hline & 1 & 0 & 1 & 4 & 2 & 2 & 1 & 0 & 0 & 1 & 0 \\
\hline & 2 & 0 & 0 & 0 & 0 & 0 & 0 & 1 & 0 & 0 & 0 \\
\hline & 3 & 0 & 0 & 0 & 0 & 0 & 0 & 0 & 0 & 1 & 0 \\
\hline & 4 & 0 & 0 & 0 & 0 & 0 & 0 & 0 & 0 & 0 & 0 \\
\hline & 5 & 0 & 0 & 0 & 0 & 0 & 0 & 0 & 0 & 0 & 0 \\
\hline
\end{tabular}

pterygium-affected persons. Groups of pterygium-affected family members were more frequent in cases. Groups of $3-5$ pterygium cases in a household occurred in $36(70.5 \%)$ of 51 pterygium families v. $1(2 \%)$ of 50 controls.

\section{Discussion}

The use of traditional eye drops was the only significant environmental factor related to the occurrence of pterygium, and this was independent of family history and the presence or absence of dry eyes. Traditional eye drops are prepared from the leaves of a plant that the Pedi call Mmale, and were used several times a day for several weeks when eyes were acutely red (personal communication in 2011 from 3 users). As nearly half of the controls reported use of these traditional eye drops, yet did not have pterygium, it is unlikely that traditional eye drops directly caused pterygium. It has been reported that blacks who used traditional medicine believed in it ${ }^{1}$ and that they also followed certain tradition $s^{16}$ such as cross-cousin marriage, ${ }^{17}$ which tends to promote hereditary conditions in an extended family. ${ }^{18}$ The use of traditional eye medicine implicates an hereditary predisposition to pterygium occurrence in this study.

Family history of pterygium, which suggests heredity, ${ }^{9}$ was found to be the most significant, and independent risk, factor for pterygium occurrence, which has not been reported before. Diagnosed pterygiumaffected key relatives were associated with pterygium occurrence, so confirming familial occurrence, which is a similar finding to that in a report on primary blepharospasm..$^{15}$ The association of diagnosed pterygium-affected relatives with pterygium cases has not been reported before. Since alleles may or may not be transmitted, this explains why some families had 1 or 2 affected individuals. The presence of pterygium-affected individuals in some families of control probands seems to oppose a hereditary effect; however, those families were of pterygium patients in whom the probands were unaffected. Having both affected and unaffected individuals in a family does not mean that the disease is not hereditary.

Familial occurrence may be due to heredity or a shared environment or both. Since excessive sunlight exposure and dust exposure were not confirmed to be associated with pterygium cases; and the affected and unaffected family members lived close together; and the affected offspring of pterygium probands, who were aged $\leq 20$ years were much fewer than the unaffected, yet both groups of offspring had similar exposure to sunlight as they were scholars; and the families of cases and controls lived in the same province that has been reported to be sunny and dry; ${ }^{14}$ and the age range of the individuals in the families of cases and controls was similar, suggesting a similar lifetime duration of exposure; we conclude that it is unlikely that excessive sunlight exposure and dust exposure were the shared environment that determined pterygium occurrence. Heredity may be the predisposing factor for the familial occurrence of pterygium. ${ }^{19}$ Moreover, heredity explains the tendency of larger families to have more affected members. ${ }^{15,20}$ Because some patients were exposed for short durations, sunlight despite low exposure may be only a trigger for pterygium to occur in predisposed individuals. As the level of education was equally low among patients and controls, and the available employment was mainly on farms (as reported before ${ }^{21}$ ), these may be reasons why controls were as excessively exposed to sunlight and dust as the cases.

An unstable tear film was infrequent in this study. This condition was negatively associated with pterygium presence, and was independent of use of eye drops and of family history. The blurring of eyesight owing to dry eyes was a reason for some controls to seek refraction. The majority of participants were female, perhaps because of male migration from rural areas to urban centres to find work, as previously reported. ${ }^{9}$

\section{Conclusions}

The use of traditional eye drops appears to be associated with pterygium occurrence in rural blacks while an unstable tear film, suggesting dry eyes, appears to be protective. Heredity, which manifested as a family history of pterygium, confirmed by having diagnosed affected relatives, was significant in pterygium occurrence. Investigations on a molecular basis for hereditary predisposition to pterygium occurrence are recommended as this will facilitate strategies to prevent pterygium.

\section{References}

1. Nxumalo N, Alaba O, Harris B, Chersich M, Goudge J. Utilization of traditional healers in South Africa and costs to patients: findings from a national household survey. J Public Health Policy 2011;32;Suppl 1:S124-136. [http://dx.doi.org/10.1057/jphp.2011.26] 


\section{RESEARCH}

2. Cameron ME. Pterygium Throughout the World. Springfield: Thomas, 1965.

3. Ukponmwan CU, Dawodu OA, Edema OF, Okojie O. Prevalence of pterygium and pingueculum among motorcyclists in Nigeria. East Afr J Med 2007; 84: 516-521.

4. Gazzard G, Saw S-M, Farook M, et al. Pterygium in Indonesia: prevalence, severity and risk factors. Br J Ophthalmol 2002;86:1341-1346. (PMID: 12446360)

5. Hill JC, Maske R. Pathogenesis of pterygium. Eye 1989;3:218-226

6. Forsius H, Maertens K, Fellman J. Changes of the eye caused by the climate in Rwanda, Africa. Ophthalmic Epidemiol 1995;2:107-13

7. Hilgers JHC. Pterygium: its incidence, heredity and aetiology. Am J Ophthalmol 1960;50:635-644 8. Islam SI, Wagoner MD. Pterygium in young members of one family. Cornea 2001;20:708-710.

9. Anguria P, Ntuli S, Carmichael T. Relationships of heredity and dry eye with pterygia in black African patients. S Afr Med J 2011;101:110.

10. Balogun MM, Ashaye AO, Ajayi BGK, Osuntokun OO. Tear break-up time in eyes with pterygia and pingueculae in Ibadan. W Afr J Med 2005;24:162-166.

11. Wong TY, Foster PJ, Johnson GJ, Seah SKL, Tan DTH. The prevalence and risk factor for pterygium in adult Chinese population in Singapore: the Tanjong Pagar survey. Am J Ophthalmol 2001;131:176-183

12. Luthra R, Nemesure BB, Wu S-Y, Xie SH, Leske MC, Barbados Eye Studies Group. Frequency and risk factors for primary pterygium in the Barbados Eye Study. Arch Ophthalmol 2001;119:1827risk fact
13. Durkin SR, Abhary S, Newland HS, Selva D, Aung T, Casson RJ. The prevalence, severity and risk factors for pterygium in central Myanmar: the Meiktila Eye Study. Br J Ophthalmol 2008;92:25-29. 4. South African Weather Service. http://www.weathersa.co.za (accessed 20 February 2010).

15. Defazio G, Martivo D, Aniello MS, et al. A family study on primary blepharospasm. J. Neurol Neurosurg Psychiatry 2006;77:252-254

16. Busia K. Medical provision in Africa - past and present. Phytother Res 2005; 19:919-923.

17. Myburgh AC, ed. Anthropology for Southern Africa. Pretoria: JL Schaik, 1991.

18. Jaouad IC, Elalaoui SC, Sbiti A, et al. Consanguineous marriages in Morocco and the consequence for the incidence of autosomal recessive disorders. J Biosoc Sci 2009;5:575-581.

9. Booth F. Heredity in one hundred patients admitted for excision of pterygia. Aust NZ J Ophthalmol 1985;13:59-61.

Bodmer W, Bonilla C. Common and rare variants in multifactorial susceptibility to common diseases. Nat Genet 2008;40:695-701.

21. Hill JC. The prevalence of corneal disease in the coloured community of a Karoo town. S Afr Med J 1985;67:723-727.

Accepted 14 June 2012. 